\title{
A precipitation-hardened high-entropy alloy with outstanding tensile properties
}

J. Y. He ${ }^{1}$, H. Wang ${ }^{1}$, H. L. Huang ${ }^{1}$, X. D. Xu' ${ }^{2}$, M. W. Chen ${ }^{2}$, Y. Wu ${ }^{1}$, X. J. Liu ${ }^{1}$, T. G. $\mathrm{Nieh}^{3}, \mathrm{~K} . \mathrm{An}^{4}$ and Z. P. Lu ${ }^{1, *}$

${ }^{1}$ State Key Laboratory for Advanced Metals and Materials, University of Science and Technology Beijing, Beijing, 100083, China

${ }^{2}$ Advanced Institute for Materials Research, Tohoku University, Sendai 980-8577, Japan

${ }^{3}$ Department of Materials Science and Engineering, the University of Tennessee, Knoxville, TN 37996, USA

${ }^{4}$ Spallation neutron source, Oak ridge national laboratory, TN 37996, USA

\section{Abstract}

Recent studies indicated that high-entropy alloys (HEAs) possess unusual structural and thermal features, which could greatly affect dislocation motion and contribute to the mechanical performance, however, a HEA matrix alone is insufficiently strong for engineering applications and other strengthening mechanisms are urgently needed to be incorporated. In this work, we demonstrate the possibility to precipitate nanosized coherent reinforcing phase, i.e., $\mathrm{L}_{2}-\mathrm{Ni}_{3}(\mathrm{Ti}, \mathrm{Al})$, in a fcc-FeCoNiCr HEA matrix using minor additions of $\mathrm{Ti}$ and $\mathrm{Al}$. Through thermomechanical processing and microstructure controlling, extraordinary balanced tensile properties at room temperature were achieved, which is due to a well combination of various hardening mechanisms, particularly precipitation hardening. The applicability and validity of the conventional strengthening theories are also discussed. The current work is a successful demonstration of using integrated strengthening approaches to manipulate the properties of fcc-HEA systems, and the resulting findings are important not only for understanding the strengthening mechanisms of metallic materials in general, but also for the future development of high-performance HEAs for industrial applications.

Keywords: High-entropy alloys; precipitation hardening; strengthening mechanisms; Mechanical properties; 3 dimensional atom probe tomography

*Corresponding author: luzp@ustb.edu.cn 


\section{Introduction}

Conventional alloy design strategy, which is usually based on one principal constituent and adds other minor elements for further optimization of properties and performances, has created a variety of metallic materials for our daily life. Recently, a revolutionary alloy design concept, namely, high-entropy alloy (HEAs) concept, was proposed and the basic idea is to simultaneously alloy multiple principal elements in equimolar or near equimolar ratios to increase the configuration entropy to stabilize the structures. Since its inception, this new family of alloys has been attracted extensive attention due to their unique properties and the related scientific importance [1-5]. Due to their high mixing entropy, these alloys tend to form single-phase structures with a high symmetry, such as fcc (face-centered cubic), bcc (body-centered cubic), and hcp (hexagonal close-packed) [4] [6-8]. They have been demonstrated to exhibit several special intrinsic characteristics, for example, high configuration entropy [9], sluggish atomic diffusion[10], and large lattice distortion $[3,11]$. These features are anticipated to enhance formation and stabilization of solid solution phases and impede dislocation motion, thereby improving the mechanical strength, particularly at high temperatures. Nevertheless, recent studies [12-14] indicate that a HEA matrix alone, especially single-phase fcc structure, is insufficiently strong for practical applications. In other words, other strengthening mechanisms are needed so that desirable mechanical properties can be obtained. While, qualitative descriptions and equations of strengthening mechanisms for traditional solid solution alloys are well established, such theories are missing for the highly concentrated HEAs because it is difficult to clearly identify their "solvent" and "solutes". Therefore, strengthening mechanisms in these emerging metallic materials must be carefully investigated so that reliable theories can be established.

FeCoNiCrMn is generally recognized as a "model" HEA with a simple fcc structure, and exhibits both outstanding ductility and fracture toughness property [12], even at 
the liquid nitrogen temperature. However, its strength is relatively low, only around $200 \mathrm{MPa}$ in the as-cast state $[13,14]$, which is far from practical structural applications. To make it useful, additional strengthening methods, without sacrificing its ductility, must be induced in the alloy and, the underlying mechanisms need to be scrutinized so that general understanding of the strengthening of HEAs can be achieved.

Along this line, Otto et al. made attempts to enhance the strength of this fcc-FeCrNiCoMn by grain refinement and found that the room-temperature yield strength of the alloy increased from 200 to $350 \mathrm{MPa}$ when the grain size was reduced from 144 to $4.4 \mu \mathrm{m}$ [13]. This work suggests grain boundary hardening can be induced in the fcc-FeCrNiCoMn alloy, but the hardening is seemingly not extraordinary. To further improve the strength without losing plastic stability, one must, therefore, rely on other mechanisms, such as precipitation hardening, which would requires a modification of the chemical composition of the alloy.

In terms of precipitation hardening in HEAs, published results appear somewhat sketchy. A few publications reported the observation of precipitation behavior in HEAs, e.g., in a mixed fcc + bcc $\mathrm{CuCr}_{2} \mathrm{Fe}_{2} \mathrm{NiMn}[15]$, a mixed fcc + bcc $\mathrm{Al}_{0.3} \mathrm{CrFe}_{1.5} \mathrm{MnNi} 0.5$ and single-phase bcc- $\mathrm{Al}_{0.5} \mathrm{CrFe}_{1.5} \mathrm{MnNi}_{0.5}[16]$. The precipitates in these HEAs were relatively bulky (generally, larger than $\mu \mathrm{m}$ in size), significantly different from the distribution of fine precipitates $(\sim \mathrm{nm})$ commonly observed in traditional precipitation-hardened alloys. Nevertheless, Yeh et al have reported the presence of nano-scale precipitates in some HEAs [5]. In this case, a distribution of extremely tiny precipitates (diameter $\sim 3-7 \mathrm{~nm}$ ) was observed in a CuCoNiCrAlFe HEA with a modulated structure. Tensile properties and possible strengthening of the alloy were unfortunately not evaluated. However, these observations are quite encouraging and suggest that proper selection of the chemical composition combined with appropriate thermomechanical treatment may offer the opportunity to manipulate precipitation strengthening of HEAs. 
In the present paper, we demonstrate that minor alloy additions of $\mathrm{Ti}$ and $\mathrm{Al}$ to a single-phase fcc-FeCoNiCr HEA can induce the formation of $\mathrm{L}_{2}$ coherent nano-size precipitates in the alloy matrix. Subsequently, both yield and ultimate tensile strengths of the alloys are drastically increased. The strengthening efficacies from various strengthening mechanisms are evaluated based on the resulting microstructure in the current highly concentrated HEA matrix.

\section{Experimental}

Two HEA compositions were prepared by vacuum arc melting: the base alloy, FeCoNiCr (in equimolar ratio) for comparison, and another with the nominal composition of $(\mathrm{FeCoNiCr}){ }_{94} \mathrm{Ti}_{2} \mathrm{Al}_{4}$ (at .\%). The alloy ingots were prepared by arc-melting a mixture of pure metals (purity larger than 99.9\%), and re-melted at least

four times to ensure homogeneity. The master ingots were then drop-casted into a copper mold with a dimension of $10 \times 10 \times 60 \mathrm{~mm}^{3}$, and subsequently tube-sealed and homogenized at $1473 \mathrm{~K}$ for $4 \mathrm{~h}$.

Two thermomechanical procedures were conducted on the alloyed HEA to obtain fine structures. The first treatment, P1, includes an initial cold rolling of $30 \%$, subsequent annealing at $1273 \mathrm{~K}$ for $2 \mathrm{~h}$, aging at $1073 \mathrm{~K}$ for $18 \mathrm{~h}$, and followed by water quenching. The second process, $\mathrm{P} 2$, includes an initial cold rolling of $70 \%$, and then aging at $923 \mathrm{~K}$ for $4 \mathrm{~h}$, followed by water quenching. Therefore, four different HEA samples were prepared, i.e., the as-homogenized FeCoNiCr (alloy A), as-cast (FeCoNiCr) ${ }_{94} \mathrm{Ti}_{2} \mathrm{Al}_{4}$ (alloy B), $\mathrm{P} 1$ and $\mathrm{P} 2$.

A CMT4105 universal electronic tensile testing machine was employed for tensile tests at room temperature with a nominal strain rate of $1 \times 10^{-3} \mathrm{~s}^{-1}$. The dog bone-shaped tensile samples had a gauge length of $20 \mathrm{~mm}$, a width of $5 \mathrm{~mm}$ and a thickness of $1.3 \mathrm{~mm}$. The surface of test samples was polished down to a 2000 -grit $\mathrm{SiC}$ paper to eliminate scratches. 
Considering the relative low accuracy of X-ray diffraction (XRD) in nano-precipitates detection, phase identification in this study was conducted by neutron diffraction, at the VULCAN instrument, beam line 7, Oak Ridge National Laboratory Spallation Neutron Source (ORNL, SNS), USA, at room temperature. The microstructure was characterized by a Zeiss Supra55 scanning electron microscope (SEM) and a JEOL ARM200 transmission electron microscope (TEM) equipped with an objective lens corrector and a thermal field-emission gun (FEG). SEM specimens were initially polished to 2000-grit SiC paper and, subsequently, electrochemically polished for the final surface clarification using a $\mathrm{HClO}_{4}: \mathrm{C}_{2} \mathrm{H}_{6} \mathrm{O}=1: 9$ solution with a direct voltage of $30 \mathrm{~V}$ at room temperature. TEM samples were primarily punched to Ф3 $\mathrm{mm}$ circle sheets and then ground to about $50 \mu \mathrm{m}$, followed by twin-jet electro-polishing using a mixed solution of $\mathrm{HNO}_{3}: \mathrm{CH}_{4} \mathrm{O}=1: 4$ with a direct voltage of $28 \mathrm{~V}$ and a current of $60 \mathrm{~mA}$ at a temperature around $233 \mathrm{~K}$.

Sharp tip specimens for atom probe tomography (APT) were made by a two-step electrochemical polishing. The $0.3 \mathrm{~mm} \times 0.3 \mathrm{~mm}$ blanks were cut by low speed diamond saw, followed by electrochemical polishing using $10 \%$ perchloric acid at a direct voltage of $15 \mathrm{~V}$, the tips were then polished by using weaker electrolyte $(2 \%)$ of perchloric acid at a direct voltage of $8 \mathrm{~V}$. Data acquisition was performed by using a local electrode atom probe (LEAP 4000HR) equipped with an energy-compensated reflectron by which the mass resolution can be greatly improved. The APT acquisition temperature was set at $\sim 60 \mathrm{~K}$ and the pulse frequency and pulse fractions were 200 $\mathrm{kHz}$ and 20\%, respectively. CAMECA Integrated Visualization and Analysis Software (IVAS 3.6.8) package was used for the data processing and three-dimensional (3D) atomic reconstruction.

Shear modulus and Poisson's ratio of polished specimens with a dimension of $5.5 \times 5.5 \times 2.5 \mathrm{~mm}^{3}$ were measured using RUSpec resonant ultrasound spectrometer, Teclab, USA. To determine the dislocation density using the Williamson-Hall method, $\mathrm{XRD}$ tests were conducted using $\mathrm{CuK} \alpha$ radiation (Rigaku Dmax 2500V) with a 
scanning $2 \theta$ range of $40^{\circ}$ to $100^{\circ}$ and a step of $0.02^{\circ}$. Annealed single crystal $\mathrm{Si}$ powder was also tested to define the instrument peak broadening in this method.

\section{Results}

\subsection{Neutron diffraction and SEM results}

Neutron diffraction patterns of the four HEA specimens, i.e., the homogenized FeCoNiCr (Alloy A) and (FeCoNiCr) ${ }_{94} \mathrm{Ti}_{2} \mathrm{Al}_{4}$ (Alloy B), and two thermomechanically processed $(\mathrm{FeCoNiCr})_{94} \mathrm{Ti}_{2} \mathrm{Al}_{4}$ alloys $\mathrm{P} 1$ and $\mathrm{P} 2$, respectively, are presented in Fig. 1. A single family of fcc peaks are clearly observed for alloy A and B. By contrast, extra series of minor peaks identified as $\mathrm{L}_{2}-\mathrm{Ni} 3(\mathrm{Ti}, \mathrm{Al})$ are detected in $\mathrm{P} 1$ and $\mathrm{P} 2$ samples, indicating the precipitation of secondary phases. It should also be noticed that, there are still two weak peaks at $\sim 1.4 \AA$ in alloy $\mathrm{A}$ and $\mathrm{B}$ and another one at $\sim 1.1 \AA$ in alloy P1 and P2 being unknown. Due to the relative low intensity and limited amount of peaks, one can hardly determine the exact phase structure they belong to. Nevertheless, the matrix of the four alloys is mainly composed of an fcc structure.

Figure 2 shows the corresponding SEM micrographs of the four kinds of HEA samples. As can be seen, both A and B alloys appear to be single-phase structure in Figs. $2 \mathrm{a}$ and $\mathrm{b}$, respectively, with only few dirt on the surface probably introduced during the electro-polishing process. In accordance with the neutron diffraction results, however, both P1 (Fig. 2c) and P2 (Fig. 2d) show a significant amount of fine precipitates. In addition to these fine precipitates, a few blocky particles at the micro-scale were observed to form near the grain boundary region in P1 (marked by arrows in Fig. 2c). Additional study of these large particles using TEM-EDX indicates that they are enriched in $\mathrm{Ni}, \mathrm{Al}$ and $\mathrm{Ti}$, and the corresponding TEM selected area electron diffraction (SAED) patterns (not shown) identify it as the $\mathrm{Ni}_{2} \mathrm{AlTi}$ phase; the results are summarized in Table 1. According to a recent work by Choudhuri et al. [17], this phase has a L2 1 Heusler-like structure (strong but brittle at room 
temperature), and is incoherent with the fcc HEA matrix. An enlarged view of the precipitate morphology is presented in Figs. 2e and 2f for P1 and P2, respectively. In P1 (Fig. 2e), two regions with distinct precipitate morphologies are observed (as marked). Region I consists of spherical particles with a size less than $40 \mathrm{~nm}$ and homogenously distributed inside the grain, whilst Region II consists of plate-like precipitates with a width larger than $70 \mathrm{~nm}$. In P2 (Fig. 2f), however, precipitates appear to be more uniform throughout the entire matrix, with a diameter ranging from 20 to $100 \mathrm{~nm}$. The $\mathrm{L}_{2} \mathrm{Ni}_{2} \mathrm{AlTi}$ particles are also found, but in a finer scale of $\sim 100$ $\mathrm{nm}$ and they appear as irregular blocks, as arrowed in Fig. 2f. Further detailed structure description and strengthening mechanism analysis of this L 21 phase are considered not important, because of the relative low volume fraction in both P1 and P2.

\subsection{TEM characterization}

Since the precipitation sequence in alloy $\mathrm{P} 1$ and $\mathrm{P} 2$ are expected to be similar with only some minor differences, for simplicity and clarity, we mainly focus on the discussion of the microstructure in P1. A representative bright field (BF) TEM image taken from P1 is presented in Figure 3a, which gives a general view of two regions of nano-precipitates. In the right insets of Fig. 3a, three SAED patterns along different Z-axes taken from Region I are shown. The main diffraction spots confirm that the matrix is indeed fcc, whilst additional weak spots observed in all the images affirm the presence of precipitates which has a superlattice L12 structure. Together with the neutron diffraction results, we can eventually identify the $\mathrm{L}_{2}$ phase as $\mathrm{Ni}_{3}(\mathrm{Ti}, \mathrm{Al})$ type $\gamma^{\prime}$ phase (hereafter denoted as $\gamma^{\prime}$ phase). Similar diffraction patterns were also obtained in Region II (e.g., the image along Z-[110] shown in the left inset of Fig. 3a), suggesting that precipitates in both regions are the same, although their morphologies are obviously different. The lattice parameter of both the disordered fcc matrix and precipitates were measured to be $0.358 \mathrm{~nm}$. The lattice mismatch appears to be 
extremely small, revealing a coherent interface between them.

Further, two corresponding bright and dark field images are shown in Figs. 3b and c. With a upper region boundary and a under twin boundary, a group of spherical $\gamma^{\prime}$ phase particles dispersed in the Region I matrix is demonstrated. To reveal the interfacial coherence, a high resolution TEM picture showing the interface between a particle and the fcc matrix is presented in Fig. 3d. The fast Fourier transformation (FFT) images indicate a (111) atomic plane, for both matrix and particle. In the figure, two groups of atoms across the interface are selected, and labeled with different colors, to conveniently distinguish each other: pink for atoms belonging to the particle and green for those of the matrix (seen in Fig. 3d). In this manner, the transition of atomic arrangement across the particle-matrix interface is directly shown. The corresponding lattice sketches are also inserted, exhibiting the typical (111) plane of atoms of the A1 crystal structure (i.e., the basic fcc structure) and $\mathrm{L}_{2}$ crystal structure, for green and pink regions respectively. The blue balls represent small constituent atoms (here are $\mathrm{Ni}, \mathrm{Fe}, \mathrm{Co}$ or $\mathrm{Cr}$ ) which compose of the A1 matrix lattice, while the orange ones stand for the large atoms of $\mathrm{Al}$ or $\mathrm{Ti}$, occupying the face centered position in the superlattice. These results provide us with a visual understanding of the particle-matrix interface structure in detail.

\subsection{Atom Probe tomography (APT) analysis}

To obtain the chemical distribution of the constituent atoms, we employed 3D-APT reconstruction of alloy P1. Atom maps in Region I in P1 with $\mathrm{Fe}, \mathrm{Co}, \mathrm{Cr}$ and $\mathrm{Ni}, \mathrm{Al}$, Ti color-coded and resolved in two boxes are given in Fig. 4a. Generally, many visible particles enriched with $\mathrm{Ni}, \mathrm{Al}, \mathrm{Ti}$ in a size of tens of nanometers are embedded in the homogeneous matrix. A $35 \% \mathrm{Ni}$ iso-concentration map is further displayed to delineate the outline of particles. In Fig. 4b, the elemental partitioning is shown in a proximity histogram constructed across the interface between the matrix and precipitates. It is noted that, in $\gamma^{\prime}$ phase particles, despite up to $50 \% \mathrm{Ni}$ concentration, 
some of the Ni sites are still taken by substitutional atoms, such as $\mathrm{Fe}, \mathrm{Co}$ and $\mathrm{Cr}$ ( $30 \%$ in total). In Region II, separate plots of each element are shown in Fig. 4c. The depletion or enrichment of each element in some regions easily reveals the plate-like precipitation morphology and its accompanied compositional separation, just as shown in the corresponding proximity histogram of elemental concentration in Fig. $4 \mathrm{~d}$. In the precipitates side (on the right-hand-side of the figure), Ni concentration almost reaches 60 at.\%, whilst $\mathrm{Fe}$ and $\mathrm{Cr}$ are largely depleted. Also, the concentration difference between the precipitate and matrix is larger, which means being more close to the components of $\mathrm{Ni}_{3} \mathrm{Al}$ compounds than the spherical particles in Region I. From the above observations, we can tentatively conclude that Region II may have initially evolved from Region I during the long aging process. Additional work to identify the kinetic path for precipitate formation is currently underway.

\subsection{Tensile properties at room temperature}

Representative tensile stress-strain curves of the four specimens are shown in Fig. 5a. The ultimate strengths of $\mathrm{A}$ and $\mathrm{B}$ samples are noted to be 453 and $503 \mathrm{MPa}$, respectively. Since there is essentially no second phase in these two alloys, the slight strength increase in the homogenized sample B $(\sim 50 \mathrm{MPa})$ is probably attributable to the solid-solution effect caused by the $\mathrm{Ti}$ and $\mathrm{Al}$ additions. After thermomechanical treatments, strengths of both P1 and P2 alloys are noted to dramatically increase, and specifically the yield and ultimate tensile strengths of P1 become 645 and $1094 \mathrm{MPa}$, respectively, without significant loss in plasticity $(\sim 39 \%)$. For the P2 sample, yield and ultimate tensile strengths are even higher at 1005 and $1273 \mathrm{MPa}$, respectively, whilst the elongation still remains at a respectable value of $17 \%$. The yield strength of over $1 \mathrm{GPa}$ is particularly noteworthy since, to the authors' knowledge, such high yield strength has not been reported in fcc-HEAs before. We can further estimate the toughness of these alloys and compare it with that of other conventional alloys. The product of strength and elongation for P1 reaches a value of $42600 \mathrm{MPa} \%$, which well 
exceeds the level of many TRIP steels (only about 15000 30000 $\mathrm{MPa} \%$ ) [18-21]. A direct comparison of the tensile strength and elongation of the current HEAs with those of several advanced steels (data from reference [19]) is presented in Fig. 5b. The current P1 and P2 HEAs are located at the upper-right above the general curve for the conventional alloys, clearly indicating that they outperform most advanced steels.

\section{Discussion}

Strengthening mechanisms in polycrystalline materials are traditionally summarized into four categories: solid-solution hardening, grain-boundary hardening, dislocation hardening, and precipitation hardening. As the four mechanisms are operating independently, yield strength is a simple summation of the four individual contributions and can be expressed as [22]:

$$
\sigma_{0.2}=\sigma_{\mathrm{A}}+\Delta \sigma_{\mathrm{S}}+\Delta \sigma_{\mathrm{G}}+\Delta \sigma_{\mathrm{D}}+\Delta \sigma_{\mathrm{P}}
$$

where $\sigma_{\mathrm{A}}=165 \mathrm{MPa}$ is the yield strength of alloy A, which is the intrinsic strength, or the so-called lattice friction strength, and $\Delta \sigma_{\mathrm{S}}, \Delta \sigma_{\mathrm{G}}, \Delta \sigma_{\mathrm{D}}$ and $\Delta \sigma_{\mathrm{P}}$ are strengthening contributions from solid solution, grain boundary, dislocations, and precipitates, respectively. In the following, we will focus on these mechanisms and evaluate their contributions to the overall strength in the current HEA individually.

\subsection{Solid solution hardening}

Traditional approaches of measuring the effect of solid-solution hardening are all based on dilute solution alloys, especially for binary systems [23, 24]. However, for HEAs, generally known as "concentrated solid-solution" systems, the terms "solute" and "solvent" lose their conventional meanings. How to evaluate, or just define, the precise contribution of solid-solution strengthening in HEAs, remains a challenge. Recently, Toda-Caraballo et al [25] made special efforts to extend the traditional solid solution hardening theories to include concentrated multicomponent alloys such as 
HEAs, however, the model still has difficulties to describe materials with complex chemical structures (for example, precipitates, a mixed fcc plus bcc structure). Fortunately, the current HEA can be simply treated as a FeCoNiCr solvent matrix containing $\mathrm{Ti}+\mathrm{Al}$ solutes, and a standard model for substitutional solid solution strengthening based on dislocation-solute elastic interactions can be directly applied to evaluate the potency of solution strengthening caused by $\mathrm{Ti}$ and $\mathrm{Al}[26,27]$, namely,

$$
\Delta \sigma_{\mathrm{S}}=\mathrm{M} \cdot \frac{G \cdot \varepsilon_{S}^{3 / 2} \cdot c^{1 / 2}}{700}
$$

where $\mathrm{G}$ is the shear modulus for the Ti2Al4 system (78.5GPa). $c$ is the total molar ratio of $\mathrm{Ti}+\mathrm{Al}$ in the simple fcc matrix, which is listed in Table $1 . \mathrm{M}=3.06$ is the Taylor factor, a factor that converts shear stress to normal stress for a fcc polycrystalline matrix. The interaction parameter $\varepsilon_{s}$ is expressed as:

$$
\varepsilon_{\mathrm{S}}=\left|\frac{\varepsilon_{G}}{1+0.5 \varepsilon_{G}}-3 \cdot \varepsilon_{a}\right|
$$

which combines the effects of elastic and atomic size mismatches, i.e., $\varepsilon_{\mathrm{G}}$ and $\varepsilon_{\mathrm{a}}$, and they are defined as:

$$
\begin{gathered}
\varepsilon_{\mathrm{G}}=\frac{1}{G} \frac{\partial G}{\partial c} \\
\varepsilon_{\mathrm{a}}=\frac{1}{a} \frac{\partial a}{\partial c}
\end{gathered}
$$

where $a$ is the lattice constant of the $\mathrm{FeCoNiCr}$ base alloy matrix.

The parameter $\varepsilon_{a}$ can be readily obtained from refined XRD patterns (lattice parameters are: $0.3578,0.3594$ and $0.3590 \mathrm{~nm}$ for $\mathrm{A}, \mathrm{P} 1$ and $\mathrm{P} 2$, respectively), while the parameter $\varepsilon_{\mathrm{G}}$ is usually negligible compared to $\varepsilon_{\mathrm{a}}$. In this case, the value of $\varepsilon_{\mathrm{s}}$ and thus $\Delta \sigma$ can be properly estimated. The strength enhancement caused by solid-solution hardening in P1 and P2 (as compared to the base alloy A) can be subsequently calculated to be $\Delta \sigma_{\mathrm{S} 1}=25.4 \mathrm{MPa}$ and $\Delta \sigma_{\mathrm{S} 2}=14.4 \mathrm{MPa}$, respectively. These values are obviously too small to account for the strength difference, suggesting that solid solution hardening is not the dominant mechanism. 


\subsection{Grain-boundary hardening}

It is also known that grain-size refinement can improve the strength of an alloy. Smaller grain size offers a higher volume fraction of grain-boundaries, which could impede dislocation motion. The relationship between yield strength and grain size can be well described by the classical Hall-Petch equation [28, 29]:

$$
\sigma_{\mathrm{y}}=\sigma_{0}+\mathrm{k}_{\mathrm{y}} / d^{1 / 2}
$$

where $\sigma_{\mathrm{y}}$ is the yield stress, $\sigma_{0}$ is again the lattice friction stress, $\mathrm{k}_{\mathrm{y}}$ is the strengthening coefficient and $\mathrm{d}$ is the average grain diameter. According to Eq. (6), yield strength increase caused by grain size difference $\left(\Delta \sigma_{\mathrm{G}}\right)$ can be expressed as:

$$
\Delta \sigma_{\mathrm{G}}=\mathrm{k}_{\mathrm{y}}\left(\mathrm{d}_{P}^{-1 / 2}-\mathrm{d}_{A}^{-1 / 2}\right)
$$

where $d_{P}$ represent the grain size of the thermomechancially processed materials. In this work, we adopt the value of $\mathrm{k}_{\mathrm{y}}$ from the FeCoNiCrMn system, that is, $226 \mathrm{MPa} \cdot \mu \mathrm{m}^{1 / 2}$ according to the study of Liu et al [30]. The average grain sizes of alloys A, P1 and P2 measured from using SEM and TEM are $\mathrm{d}_{\mathrm{A}}=289.7 \mu \mathrm{m}$, $\mathrm{d}_{\mathrm{P} 1}=15.7 \mu \mathrm{m}$, and $\mathrm{d}_{\mathrm{P} 2}=2.8 \mu \mathrm{m}$, respectively. The current alloys are noted to contain only a few twins. Even including these twin boundaries in the calculations, we obtain $\Delta \sigma_{\mathrm{G} 1}=43.7 \mathrm{MPa}$ and $\Delta \sigma_{\mathrm{G} 2}=122.6 \mathrm{MPa}$. The grain boundary contribution in P2 alloy is almost three times as much as that in the P1 alloy. However, both values are relatively small to account for the total strength increase.

\subsection{Dislocation hardening}

Plastic deformation results from the movement of mobile dislocations, and these dislocations interact with each other, then impede their own motion. In general, a higher dislocation density leads to a higher yield strength. A Bailey-Hirsch formula [31] is applied here to describe the relationship as:

$$
\Delta \sigma_{\mathrm{D}}=M \alpha G b \rho^{1 / 2}
$$

where $\alpha=0.2$ is a constant for fcc metals, $\rho$ stands for the dislocation density, and

$\mathrm{b}$ is the burger vector, for a fcc structure, $\mathrm{b}=\sqrt{ } 2 / 2 \times \mathrm{a}_{\mathrm{Ti2} 2 \mathrm{Al} 4}=0.255 \mathrm{~nm}$ (see 12 
reference [32]).

We roughly estimated the dislocation density through the Williamson-Hall method, a widely used first approximation to assess the effects of micro strain and crystallite size $[33,34]$. In this approach, the true XRD peak broadening $\beta$ (the observed peak broadening deducting the instrument broadening) consists of two parts: the crystallite size broadening $\beta_{G}$ and the strain broadening $\beta_{S}[35,36]$, and based on the assumption of Cauchy-type function, they are:

$$
\begin{gathered}
\beta=\beta_{G}+\beta_{S} \\
\beta_{G}=\mathrm{K} \lambda /(D \cdot \cos \theta) \\
\beta_{S}=4 \varepsilon \cdot \tan \theta
\end{gathered}
$$

where $K \sim 0.9$ is a constant, $\lambda=0.15405 \mathrm{~nm}$ is the wavelength of $\mathrm{Cu}$ Ka radiation, $\mathrm{D}$ is the crystallite size, $\varepsilon$ is the micro strain, and $\theta$ is the Bragg angle of the certain peak. Focusing on the micro strain $\varepsilon$ only, Eq. (9) can be rewritten as:

$$
\beta \cos \theta=\mathrm{K} \lambda / D+(4 \sin \theta) \cdot \varepsilon
$$

The slope of the linear fit of the $\beta \cos \theta-4 \sin \theta$ plot determines the parameter $\varepsilon$. Such plots for P1 and P2 are shown in Fig. 6. It is seen that, the micro strain of P2, i.e., $\varepsilon_{2}=0.102$, with a relative small positive intercept of 0.03 resulting from the experimental errors. However, the micro strain for P1, i.e., the $\varepsilon_{1}$ value, is nearly zero $(\sim-0.002)$. This kind of phenomenon has also be observed in another alloy system [37] in which it was suggested to be caused by the fact that the fully annealed structure has few dislocations. Here, we believe the occurrence of a similar situation in P1, which was heat-treated 2 hours at a relatively high temperature of $1273 \mathrm{~K}$ (above $0.75 \mathrm{Tm}$ ). Considering the data and pattern refinement error, it is reasonable to treat the micro strain in $\mathrm{P} 1$ as $\varepsilon_{1}=0$.

The dislocation density, can then be derived from the micro strain above [34, 38]:

$$
\rho=2 \sqrt{3} \cdot \varepsilon /(D b)
$$

from which, the dislocation density in $\mathrm{P} 1$ and $\mathrm{P} 2$ can be determined as $\rho 1 \approx 0$ and 
$\rho 2=5.02 \times 10^{14} \mathrm{~m}^{-2}$. Inserting these values into Eq. (8), the yield strength increment from dislocation strengthening is evaluated as $\Delta \sigma_{\mathrm{D} 1}=0$ and $\Delta \sigma_{\mathrm{D} 2}=$ 274.5 MPa, in $\mathrm{P} 1$ and $\mathrm{P} 2$, respectively. The result indicates that dislocation hardening plays a somewhat important role on the strength of P2. It also suggests that annealing at the intermediate temperature of $923 \mathrm{~K}$ is insufficient to annihilate the large amount of dislocations created during the heavy cold work (70\%).

\subsection{Precipitation hardening}

As shown in Fig 2, both P1 and P2 are full of fine precipitates and these precipitates are expected to produce hardening, either through a dislocation by-pass mechanism (Orowan-type) or particle shearing mechanism. Generally, Orowan mechanism occurs when the radius of particles exceeds a critical value or is incoherent with the matrix, however, shearing mechanism would dominate when precipitates are sufficiently small and coherent. Based on the current precipitate morphology, particle shearing is expected to take the control. We will, therefore, focus our discussion on this mechanism in the following.

As discussed earlier, the microstructure consists of two different regions each with its own precipitate size and distribution. In this case, a simple composite model is applicable to estimate the strength, namely,

$$
\sigma_{\mathrm{P} 1}=\sigma_{\mathrm{I}} \cdot C_{I}+\sigma_{\mathrm{II}} \cdot C_{I I}
$$

where $\sigma_{\mathrm{P} 1}$ is the overall strength, $\sigma_{\mathrm{I}}$ and $\sigma_{\mathrm{II}}$ represent the intrinsic strength of region 1 and 2, respectively, and $\mathrm{C}_{\mathrm{I}}$ and $\mathrm{C}_{\mathrm{II}}$ are the volume fractions of Region I and II, respectively. Many of the precipitates in Region II are noted to be actually plate-like, but to simplify our analysis, we will treat these particles as spherical. The fraction, size and spacing of precipitates are evaluated from the microstructural observation and summarized in Table 2.

In the calculation of the effect of particles sheared by dislocations, three

contributing factors are considered and they are particle-matrix coherency $\left(\Delta \sigma_{\mathrm{CS}}\right)$, 
modulus mismatch $\left(\Delta \sigma_{\mathrm{MS}}\right)$ and atomic ordering $\left(\Delta \sigma_{\mathrm{OS}}\right)$ [39-41]. The former two make contributions prior to the shearing, while the latter one contributes during the shearing. In principle, the larger one of $\Delta \sigma_{\mathrm{CS}}+\Delta \sigma_{\mathrm{MS}}$ and $\Delta \sigma_{\mathrm{OS}}$ determines the resultant contribution in these sequential processes. The equations for these contributions $\operatorname{are}[42]$

$$
\begin{gathered}
\Delta \sigma_{\mathrm{CS}}=M \cdot \alpha_{\varepsilon}(G \cdot \varepsilon)^{3 / 2}\left(\frac{r f}{0.5 G b}\right)^{1 / 2} \\
\Delta \sigma_{\mathrm{MS}}=M \cdot 0.0055(\Delta G)^{3 / 2}\left(\frac{2 f}{G}\right)^{1 / 2}\left(\frac{r}{b}\right)^{3 m / 2-1} \\
\Delta \sigma_{\mathrm{OS}}=M \cdot 0.81 \frac{\gamma_{A P B}}{2 b}\left(\frac{3 \pi f}{8}\right)^{1 / 2}
\end{gathered}
$$

where $\alpha_{\varepsilon}=2.6$ for fcc structure, $\mathrm{m}=0.85, \varepsilon \approx 2 / 3 \cdot(\Delta a / a)$ is the constrained lattice parameter mismatch, with $(\Delta a / a)=0.0026$ in this work, where $\Delta a$ is the difference of lattice constant between $\mathrm{Ni}_{3}(\mathrm{Ti}, \mathrm{Al})$ phase and the fcc matrix of $\mathrm{P} 1$ and P2 calculated from the XRD results; $f$ is the volume fraction of the precipitates, $\Delta G$ is the shear modulus mismatch between precipitates and matrix, and $\gamma_{A P B}$ is the anti-phase boundary energy of the precipitates, $\Delta G=81-77=4 G P a, \gamma_{A P B}=$ $0.12 \mathrm{~J} / \mathrm{m}^{2}$ are adopted from the corresponding data of $\mathrm{Ni}_{3} \mathrm{Al}$ precipitates in Ni-based superalloys [43]. The calculated individual values of $\Delta \sigma_{\mathrm{CS}}, \Delta \sigma_{\mathrm{MS}}$ and $\Delta \sigma_{\mathrm{OS}}$ are listed in Table 3, and the final strength increment from shearing $\Delta \sigma_{\mathrm{SH}}$ is determined to be $\Delta \sigma_{\mathrm{SH} 1-\mathrm{I}}=305.6 \mathrm{MPa}$ and $\Delta \sigma_{\mathrm{SH} 1-\mathrm{II}}=371.9 \mathrm{MPa}$ for Regions I and II in sample $\mathrm{P} 1$, respectively, and $\Delta \sigma_{\mathrm{SH} 2-\mathrm{Ni} 3(\mathrm{Ti}, \mathrm{Al})}=327.7 \mathrm{MPa}$ in sample $\mathrm{P} 2$. Consequently, the overall hardening contributed by precipitates in samples P1 and P2 are $\Delta \sigma_{\mathrm{P} 1}=326.7 \mathrm{MPa}$ and $\Delta \sigma_{\mathrm{P} 2}=327.7 \mathrm{MPa}$, respectively. This result shows that the two alloys actually have a similar strengthening effect from precipitation.

Based on the discussion above, the yield strengths of P1 and P2 HEAs are calculated as $\sigma_{1}=560.8 \mathrm{MPa}$ and $\sigma_{2}=904.2 \mathrm{MPa}$. For clarity, we summarize a column chart (Fig. 7) to directly show the strength contributions from the four individual mechanisms as well as the overall contributions (right column). It is apparent that the predicted data are in reasonable agreement with the experimental 
values (marked by the black and red dots). The small discrepancy may be attributable to a couple of reasons. First, the precipitates in Region II of P1, are considered to be spherical in the models to simplify calculations, however, many of them are actually in plate-like shape. Irregular plate-shaped particles are expected to produce more resistance to plastic flow as compared to smooth spherical particles. Secondly, texture difference actually exists, according to the Neutron diffraction results before. It could be developed during the cold-rolling and recrystallization process in present HEAs, according to the reported results by Dan recently [44], which can to some degree affect the overall strength of the materials. Furthermore, in our calculations, several intrinsic parameters (e.g., $\Delta \mathrm{G}$ and $\gamma_{A P B}$ ) are borrowed from Ni-based superalloys. Nevertheless, the agreement between experiments and calculations is quite satisfactory. It is especially noted that, in the thermomechanically processed P1 and $\mathrm{P} 2$, precipitation hardening offers the largest strength increment. The P2 alloy, in particular, shows a much higher strength yet still keeps a respectable ductility, due to a good utilization of various hardening mechanisms: grain boundary hardening, dislocation hardening, and most importantly, the precipitation hardening.

\section{Conclusion}

As elaborated above, for the first time, we demonstrate that a minor $\mathrm{Ti}$ and $\mathrm{Al}$ alloying addition can produce a fine dispersion of $\mathrm{L} 12$ coherent nano-precipitates in a fcc HEA alloy by proper thermomechanical treatments. These nano-precipitates can drastically enhance the strength of the alloy without compromising its tensile ductility.

We have presented two examples to illustrate the strengthening effects. The first example is a HEA (alloy P1), whose structure is composed of a mixture of two precipitate morphologies: Region I consists of nano-precipitates less than 40nm in size, while Region II consists of particles coarser than $100 \mathrm{~nm}$. All of these 16 
nano-scaled precipitates are identified to be the $\mathrm{L}_{2} \mathrm{Ni}_{3}(\mathrm{Ti}, \mathrm{Al})$-type $\gamma^{\prime}$ phase. This simple composites structure results in a $645 \mathrm{MPa}$ yield strength with an outstanding $40 \%$ elongation. Precipitation hardening is the dominant strengthening mechanism in this alloy, which contributes a strength increment of about $326.7 \mathrm{MPa}$. In the second example (alloy P2), the alloy consists of very fine dispersion of nano-precipitates, main the coherent $\gamma^{\prime}$ phase, although there are also minor nano-scale Ni2AlTi particles. This alloy exhibits even higher yield strength of over $1 \mathrm{GPa}$, but still keeps a reliable $17 \%$ tensile ductility. The exceptionally high yield strength results from contributions of precipitation hardening (327.7 MPa), dislocation hardening (274.5 MPa), and grain boundary hardening (122.6 MPa).

In summary, we have shown a successful exploration to find a way for effectively strengthening fcc-HEA systems using a controllable thermomechanical procedure. The resultant microstructure consists of precipitates with an $\mathrm{L}_{2}$-structure and structurally coherent with their fcc alloy matrices. It bear great resemblance to that of $\gamma^{\prime}-\gamma$ Ni superalloys, which are the cornerstone of high-temperature gas turbine engine materials. Our findings open a new door for the future development of HEAs for high-temperature structural applications.

\section{Acknowledgements}

This research was supported by National Natural Science Foundation of China (51451001, 5153000431, 51422101 and 51271212, 51371003), 111 Project (B07003), International S\&T Cooperation Program of China (2015DFG52600) and Program for Changjiang Scholars and Innovative Research Team in University (IRT_14R05). TGN acknowledge the support of US National Science Foundation under Contract DMR-1408722. 


\section{References}

[1] Y. J. Zhou, Y. Zhang, Y. L. Wang, G. L. Chen, Microstructure and compressive properties of multicomponent $\mathrm{Al}_{\mathrm{x}}(\mathrm{TiVCrMnFeCoNiCu})_{100-\mathrm{x}}$ high-entropy alloys, Mater. Sci. Eng., A 454-455 (2007) 260-265.

[2] Y. J. Zhou, Y. Zhang, Y. L. Wang, G. L. Chen, Solid solution alloys of AlCoCrFeNiTix with excellent room-temperature mechanical properties, Appl. Phys. Lett. 90 (2007) 181904.

[3] J. W. Yeh, S. Y. Chang, Y. D. Hong, S. K. Chen, S. J. Lin, Anomalous decrease in $\mathrm{X}$-ray diffraction intensities of $\mathrm{Cu}-\mathrm{Ni}-\mathrm{Al}-\mathrm{Co}-\mathrm{Cr}-\mathrm{Fe}-\mathrm{Si}$ alloy systems with multi-principal elements, Mater. Chem. Phys. 103 (2007) 41-46.

[4] B. Cantor, I. T. H. Chang, P. Knight, A. J. B. Vincent, Microstructural development in equiatomic multicomponent alloys, Mater. Sci. Eng., A 375-377 (2004) 213-218.

[5] J. W. Yeh, S. K. Chen, S. J. Lin, J. Y. Gan, T. S. Chin, Nanostructured high-entropy alloys with multiple principal elements novel alloy design concepts and outcomes, Adv. Eng. Mater. 6 (2004) 299.

[6] O. N. Senkov, J. M. Scott, S. V. Senkova, D. B. Miracle, C. F. Woodward, Microstructure and room temperature properties of a high-entropy TaNbHfZrTi alloy, J. Alloy. Compd. 509 (2011) 6043-6048.

[7] O. N. Senkov, S. V. Senkova, C. F. Woodward, Effect of aluminum on the microstructure and properties of two refractory high-entropy alloys, Acta Mater. 68 (2014) 214-228.

[8] K. M. Youssef, A. J. Zaddach, C. Niu, D. L. Irving, C. C. Koch, A Novel Low-Density, High-Hardness, High-entropy Alloy with Close-packed Single-phase Nanocrystalline Structures, Mater. Res. Lett. (2014) 1-5.

[9] J. W. Yeh, Alloy Design Strategies and Future Trends in High-Entropy Alloys, JOM 65 (2013) 1759-1771.

[10] K. Y. Tsai, M. H. Tsai, J. W. Yeh, Sluggish diffusion in Co-Cr-Fe-Mn-Ni high-entropy alloys, Acta Mater. 61 (2013) 4887-4897.

[11] W. Guo, W. Dmowski, J. Y. Noh, P. Rack, P. K. Liaw, T. Egami, Local Atomic Structure of a High-Entropy Alloy: An X-Ray and Neutron Scattering Study, Metall. Mater. Trans., A 44 (2012) 1994-1997.

[12] B. Gludovatz, A. Hohenwarter, D. Catoor, E. H. Chang, E. P. George, R. O. Ritchie, A fracture-resistant high-entropy alloy for cryogenic applications. Science 345 (2014) 1153-1158.

[13] F. Otto, A. Dlouhý, C. Somsen, H. Bei, G. Eggeler, E. P. George, The influences of temperature and microstructure on the tensile properties of a $\mathrm{CoCrFeMnNi}$ high-entropy alloy, Acta Mater. 61 (2013) 5743-5755.

[14] Y. Wu, W. H. Liu, X. L. Wang, D. Ma, A. D. Stoica, T. G. Nieh, Z. B. He, Z. P. $\mathrm{Lu}$, In-situ neutron diffraction study of deformation behavior of a multi-component high-entropy alloy, Appl. Phys. Lett. 104 (2014) 051910.

[15] B. Ren, Z. X. Liu, B. Cai, M. X. Wang, L. Shi, Aging behavior of a 
CuCr2Fe2NiMn high-entropy alloy, Mater. Design 33 (2012) 121-126.

[16] S. T. Chen, W. Y. Tang, Y. F. Kuo, S. Y. Chen, C. H. Tsau, T. T. Shun, J. W. Yeh, Microstructure and properties of age-hardenable AlxCrFe1.5MnNi0.5 alloys, Mater.

Sci. Eng., A 527 (2010) 5818-5825.

[17] D. Choudhuri, T. Alam, T. Borkar, B. Gwalani, A. S. Mantri, S. G. Srinivasan, M. A. Gibson, R. Banerjee, Formation of a Huesler-like L21 phase in a CoCrCuFeNiAlTi high-entropy alloy, Scripta Mater. 100 (2015) 36-39.

[18] V. F. Zackay, E. R. Parker, D. Fahr, B. Bush, The enhancement of ductility on high strength steels, Trans ASM 60 (1967) 8.

[19] Y. Gan, Y. Q. Weng, H. Dong, Advanced Steels: The Recent Scenario in Steel Science and Technology, Metallurgical Industry Press, Beijing and Springer, 2011, pp. 372.

[20] G. Krauss, Martensite in Steel: Strength and Structure, Mater. Sci. Eng., A 273-275 (1999) 40-57.

[21] S. J. Kim, C. G. Lee, T. H. Lee, C. S. Oh, Effect of $\mathrm{Cu}, \mathrm{Cr}$ and $\mathrm{Ni}$ on mechanical properties of 0.15 wt.\% C TRIP-aided cold rolled steels, Scripta Mater. 48 (2003) 539-544.

[22] N. Kamikawa, K. Sato, G. Miyamoto, M. Murayama, N. Sekido, K. Tsuzaki, T. Furuhara, Stress-strain behavior of ferrite and bainite with nano-precipitation in low carbon steels, Acta Mater. 83 (2015) 383-396.

[23] R. L. Fleischer, Substitutional solution hardening, Acta Metall. (1963) 11.

[24] T. H. Courtney, Mechanical behavior of materials, McGraw-Hill Press, 1990.

[25] I. Toda-Caraballo, P. E. J. Rivera-Díaz-del-Castillo, Modelling solid solution hardening in high entropy alloys, Acta Mater. 85 (2015) 14-23.

[26] C. A. Schuh, T. G. Nieh, H. Iwasaki, The effect of solid solution W additions on the mechanical properties of nanocrystalline Ni, Acta Mater. 51 (2003) 431-443.

[27] J. Y. He, W. H. Liu, H. Wang, Y. Wu, X. J. Liu, T. G. Nieh, Z. P. Lu, Effects of Al addition on structural evolution and tensile properties of the FeCoNiCrMn high-entropy alloy system, Acta Mater. 62 (2014) 105-113.

[28] E. O. Hall, The deformation and Ageing of Mild Steel III Discussion of Results, Proc. Phys. Soc., Sect B 64 (1951).

[29] N. J. Petch, The cleavage Strength of Polycristals, J. Iron Steel Inst. 174 (1953).

[30] W. H. Liu, Y. Wu, J. Y. He, T. G. Nieh, Z. P. Lu, Grain growth and the Hall-Petch relationship in a high-entropy FeCrNiCoMn alloy, Scripta Mater. 68 (2013) 526-529.

[31] T. H. Courtney, Mechanical behavior of materials, Long Grove Press, Waveland, 2005.

[32] J. Y. He, C. Zhu, D. Q. Zhou, W. H. Liu, T. G. Nieh, Z. P. Lu, Steady state flow of the FeCoNiCrMn high entropy alloy at elevated temperatures, Intermetallics 55 (2014) 9-14.

[33] G. K. Williamson, W. H. Hall, X-RAY LINE BROADENING FROM FILED ALUMINIUM AND WOLFRAM, Acta Metall. 1 (1953) 22-31.

[34] G. K. Williamson, R. E. III. Smallman, Dislocation densities in some annealed 
and cold-worked metals from measurements on the X-ray debye-scherrer spectrum, Philos. Mag. 1 (1956) 34-46.

[35] M. Karolus, E. Łągiewka, Crystallite size and lattice strain in nanocrystalline NiMo alloys studied by Rietveld refinement, J. Alloy. Compd. 367 (2004) 235-238. [36] S. Kumari, D. K. Singh, P. K. Giri, Strain Anisotropy in Freestanding Germanium Nanoparticles Synthesized by Ball Milling, J. Nanosci. Nanotechno. 9 (2009) 5231-5236.

[37] G. Sharma, P. Mukherjee, A. Chatterjee, N. Gayathri, A. Sarkar, J. K. Chakravartty, Study of the effect of $\alpha$ irradiation on the microstructure and mechanical properties of nanocrystalline Ni, Acta Mater. 61 (2013) 3257-3266.

[38] Y. H. Zhao, X. Z. Liao, Z. Jin, R. Z. Valiev, Y. T. Zhu, Microstructures and mechanical properties of ultrafine grained $7075 \mathrm{Al}$ alloy processed by ECAP and their evolutions during annealing, Acta Mater. 52 (2004) 4589-4599.

[39] H. Wen, T. D. Topping, D. Isheim, D. N. Seidman, E. J. Lavernia, Strengthening mechanisms in a high-strength bulk nanostructured $\mathrm{Cu}-\mathrm{Zn}-\mathrm{Al}$ alloy processed via cryomilling and spark plasma sintering, Acta Mater. 61 (2013) 2769-2782.

[40] K. Ma, H. Wen, T. Hu, T. D. Topping, D. Isheim, D. N. Seidman, E. J. Lavernia, J. M. Schoenung, Mechanical behavior and strengthening mechanisms in ultrafine grain precipitation-strengthened aluminum alloy, Acta Mater. 62 (2014) 141-155.

[41] D. N. Seidman, E. A. Marquis, D. C. Dunand, Precipitation strengthening at ambient and elevated temperatures of heat-treatable $\mathrm{Al}(\mathrm{Sc})$ alloys, Acta Mater. 50 (2002) 4021-4035.

[42] C. Booth-Morrison, D. C. Dunand, D. N. Seidman, Coarsening resistance at $400^{\circ} \mathrm{C}$ of precipitation-strengthened Al-Zr-Sc-Er alloys, Acta Mater. 59 (2011) 7029-7042.

[43] A. S. Argon, T. M. Pollock, Creep resistance of CMSX-3 nickel base superalloy single crystals, Acta Mater. 40 (1992) 30.

[44] G. Dan Sathiaraj, P. P. Bhattacharjee, Analysis of microstructure and microtexture during grain growth in low stacking fault energy equiatomic CoCrFeMnNi high entropy and Ni-60 wt.\% Co alloys, J. Alloy. Compd. 637 (2015) 267-276. 


\section{Captions}

Table 1 Chemical compositions of different phases in high-entropy alloys A, B, P1 and P2 by TEM-EDX measurements (at.\%).

Table 2 Fraction, size and spacing data of precipitates in P1 and P2 alloys. Specially, in Region II of alloy P1, the spacing and radius data are calculated in width direction of the plates. The strengthening effect of the Ni2AlTi phase is negligible due to its low volume fraction.

Table 3 Strength contributions during shearing process, showing the total strength increment derived from the shearing mechanism.

Figure 1 Neutron diffraction patterns of the four HEA samples.

Figure 2 SEM micrographs of electrochemical polished HEAs; (a) alloy A, (b) alloy B, (c) alloy P1 and (d) alloy P2 at low magnification. An enlarged view of the precipitate morphology is given in (e) and (f) for alloy $\mathrm{P} 1$ and $\mathrm{P} 2$, respectively.

Figure 3 Bright TEM field image of Region I and II (a); (b) and (c) are the corresponding bright and dark field images showing the particles distribution in Region I, (d) high-resolution TEM image showing the interface between one single nano-particle and fcc matrix, with relative FFT patterns are shown in the left; the atomic arrangement are directly distinguished.

Figure 4 APT results in P1. For Region I; two boxes of atom maps with $\mathrm{Fe}, \mathrm{Co}, \mathrm{Cr}$ 
and $\mathrm{Al}, \mathrm{Ni}$, Ti separately and one box with $35 \% \mathrm{Ni}$ iso-concentration surface showing the outline of particles (a), and (b) the proximity histogram constructed across the interface between the matrix and precipitates. For Region II: atom map of each component showing a plate-like structure (c), and (d) the proximity histogram indicating a larger difference of element distribution.

Figure 5 Tensile properties of alloys A, B, P1 and P2 at room temperature (a), and the map of ultimate tensile strength-ductility combinations of various advanced steels including P1 and P2 HEAs (b), showing great advantage of the current HEAs.

Figure 6 The peak broadening $\beta$ as a function of $4 \tan \theta$; the slope of the linear fit shows the value of micro strain $\varepsilon$.

Figure 7 The strength contributions from different hardening mechanisms. The calculation values agree well with the experimental data. 
Graphical Abstract

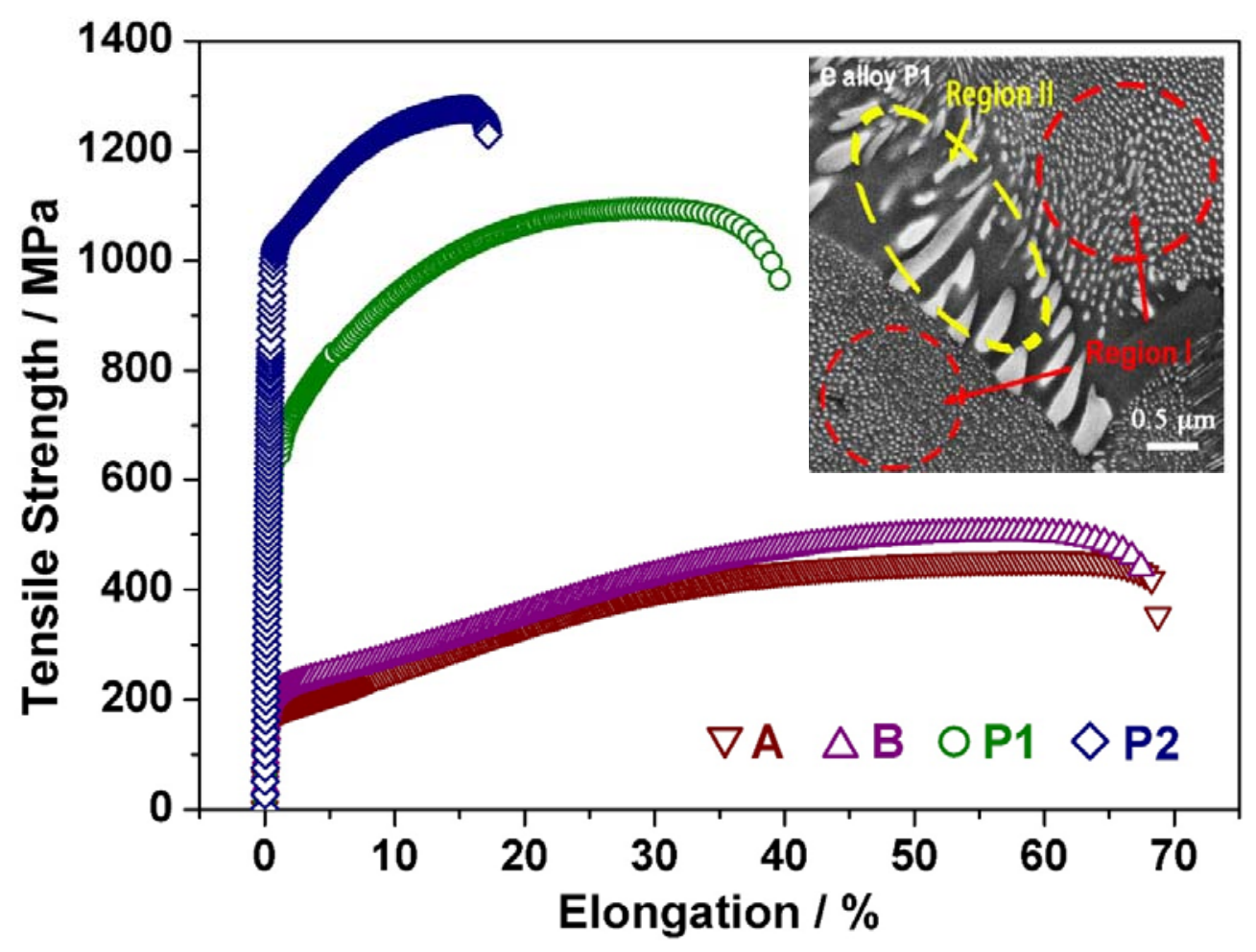


Table 1

\begin{tabular}{|c|c|c|c|c|c|c|c|}
\hline \multirow[t]{2}{*}{ Alloys } & \multirow[t]{2}{*}{ Phases } & \multicolumn{6}{|c|}{ Chemical compositions (at.\%) } \\
\hline & & Al & Ti & Cr & Fe & Co & $\mathbf{N i}$ \\
\hline A & matrix & - & - & $23.1 \pm 0.4$ & $25.9 \pm 0.7$ & $24.3 \pm 0.9$ & $24.7 \pm 1.0$ \\
\hline B & matrix & $4.4 \pm 0.1$ & $2.1 \pm 0.1$ & $22.0 \pm 0.2$ & $24.1 \pm 0.2$ & $23.3 \pm 0.2$ & $24.1 \pm 0.3$ \\
\hline \multirow{3}{*}{$\mathrm{P} 1$} & matrix & $1.3 \pm 0.1$ & $0.8 \pm 0.1$ & $25.8 \pm 0.1$ & $24.4 \pm 0.2$ & $26.1 \pm 0.2$ & $21.6 \pm 0.2$ \\
\hline & $\gamma^{\prime}$ & $8.4 \pm 0.1$ & $2.1 \pm 0.2$ & $11.6 \pm 0.2$ & $13.3 \pm 0.2$ & $17.4 \pm 0.3$ & $47.1 \pm 0.4$ \\
\hline & $\mathrm{Ni}_{2} \mathrm{AlTi}$ & $22.3 \pm 0.2$ & $17.4 \pm 0.2$ & $3.4 \pm 0.1$ & $5.0 \pm 0.2$ & $22.2 \pm 0.3$ & $31.7 \pm 0.4$ \\
\hline \multirow{3}{*}{$\mathrm{P} 2$} & matrix & $2.2 \pm 0.1$ & $0.2 \pm 0.1$ & $26.8 \pm 0.4$ & $26.7 \pm 0.4$ & $25.1 \pm 0.4$ & $19.0 \pm 0.4$ \\
\hline & $\gamma^{\prime}$ & $6.3 \pm 0.1$ & $2.7 \pm 0.1$ & $19.2 \pm 0.3$ & $20.2 \pm 0.3$ & $21.2 \pm 0.3$ & $30.4 \pm 0.4$ \\
\hline & $\mathrm{Ni}_{2} \mathrm{AlTi}$ & $18.6 \pm 0.2$ & $14.5 \pm 0.2$ & $3.1 \pm 0.1$ & $6.2 \pm 0.2$ & $19.3 \pm 0.3$ & $38.3 \pm 0.4$ \\
\hline
\end{tabular}

Table 2

\begin{tabular}{cccccc}
\hline Alloys & $\begin{array}{c}\text { Regions } \\
\text { or particles }\end{array}$ & $\begin{array}{c}\text { Region } \\
\text { fraction } \\
\text { C (\%) }\end{array}$ & $\begin{array}{c}\text { Precipit } \\
\text { ates fraction } \\
\mathbf{f ~ ( \% )}\end{array}$ & $\begin{array}{c}\text { Precipit } \\
\text { ates radius } \\
\text { r (nm) }\end{array}$ & $\begin{array}{c}\text { Particle } \\
\text { spacing } \\
\text { Lp (nm) }\end{array}$ \\
\hline \multirow{2}{*}{$\mathrm{P} 1$} & $\mathrm{I}$ & 68.1 & 23.3 & 12.6 & 17.2 \\
& $\mathrm{II}$ & 31.9 & 16.2 & 46.3 & 90.9 \\
\hline \multirow{2}{*}{$\mathrm{P} 2$} & $\gamma^{\prime}$ & - & 26.8 & 9.7 & 11.3 \\
& $\mathrm{Ni}_{2} \mathrm{AlTi}$ & - & 2.77 & 25.9 & 182.9 \\
\hline
\end{tabular}

Table 3

\begin{tabular}{|c|c|c|c|c|c|c|}
\hline Alloys & $\begin{array}{l}\text { Regions } \\
\text { or particles }\end{array}$ & $\begin{array}{l}\Delta \sigma_{\mathrm{CS}} \\
\quad(\mathrm{MPa})\end{array}$ & $\begin{array}{l}\Delta \sigma_{\mathrm{MS}} \\
\quad(\mathrm{MPa})\end{array}$ & $\begin{array}{l}\Delta \sigma_{\mathrm{OS}} \\
\quad(\mathrm{MPa})\end{array}$ & $\begin{array}{l}\Delta \sigma_{\mathrm{CS}} \\
+\Delta \sigma_{\mathrm{MS}} \\
\quad(\mathrm{MPa}) \\
\end{array}$ & $\begin{array}{l}\Delta \sigma_{\mathrm{SH}} \\
\quad(\mathrm{MPa})\end{array}$ \\
\hline \multirow{2}{*}{ P1 } & I & 216.8 & 29.8 & 305.6 & 246.6 & 305.6 \\
\hline & II & 346.5 & 35.6 & 254.8 & 382.1 & 382.1 \\
\hline $\mathrm{P} 2$ & - & 204.0 & 29.8 & 327.7 & 233.8 & 327.7 \\
\hline
\end{tabular}


Figure 1
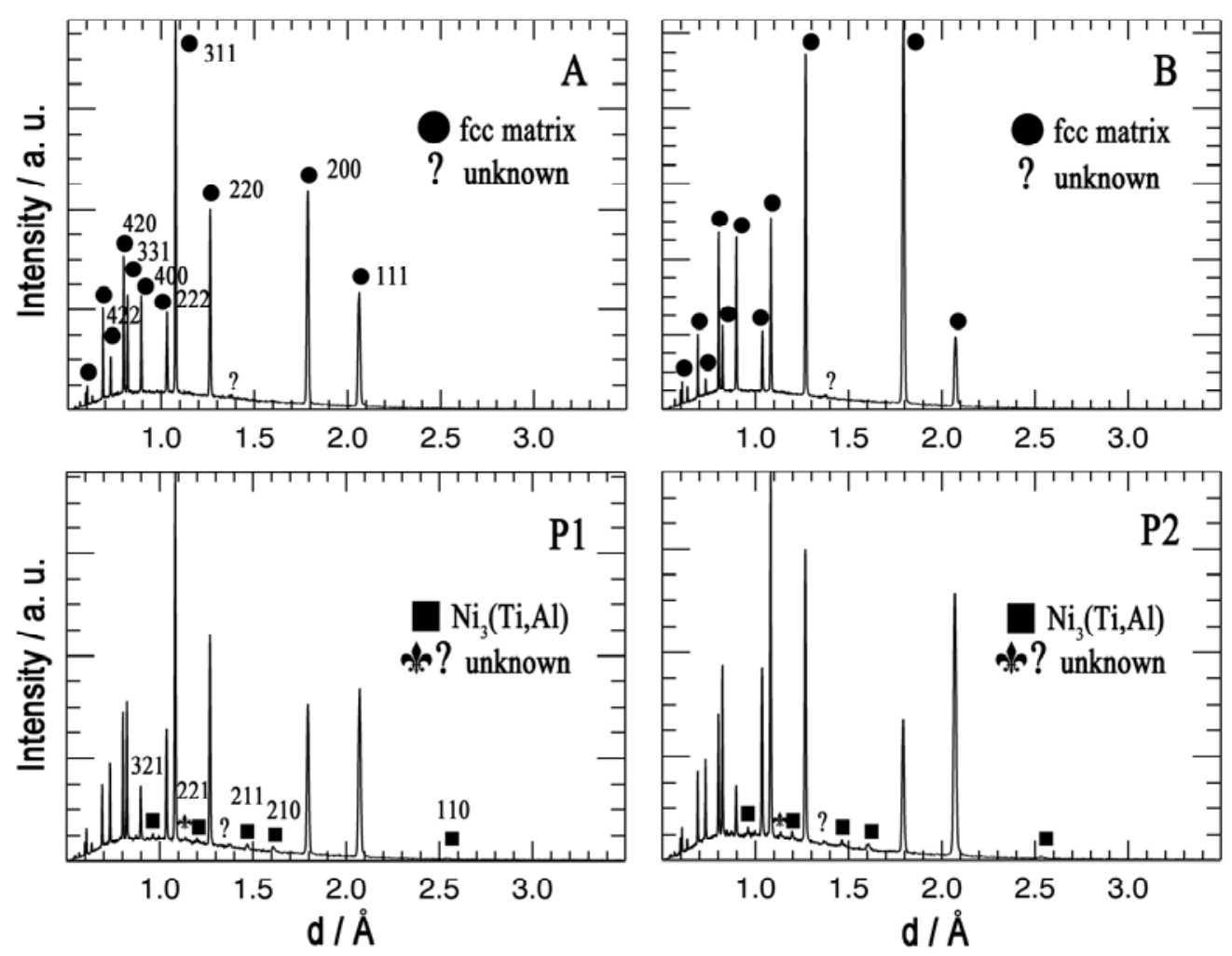
Figure 2
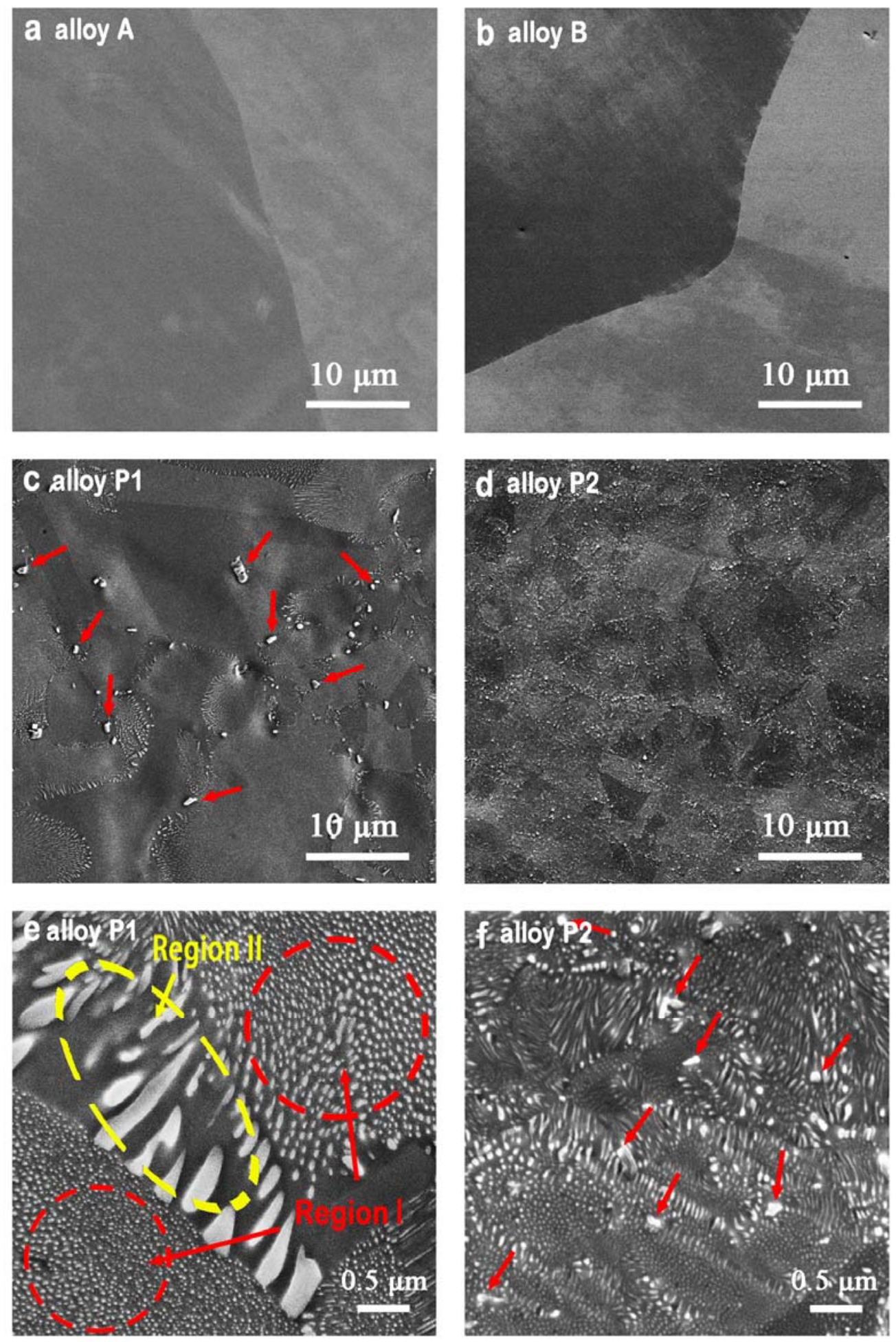
Figure 3
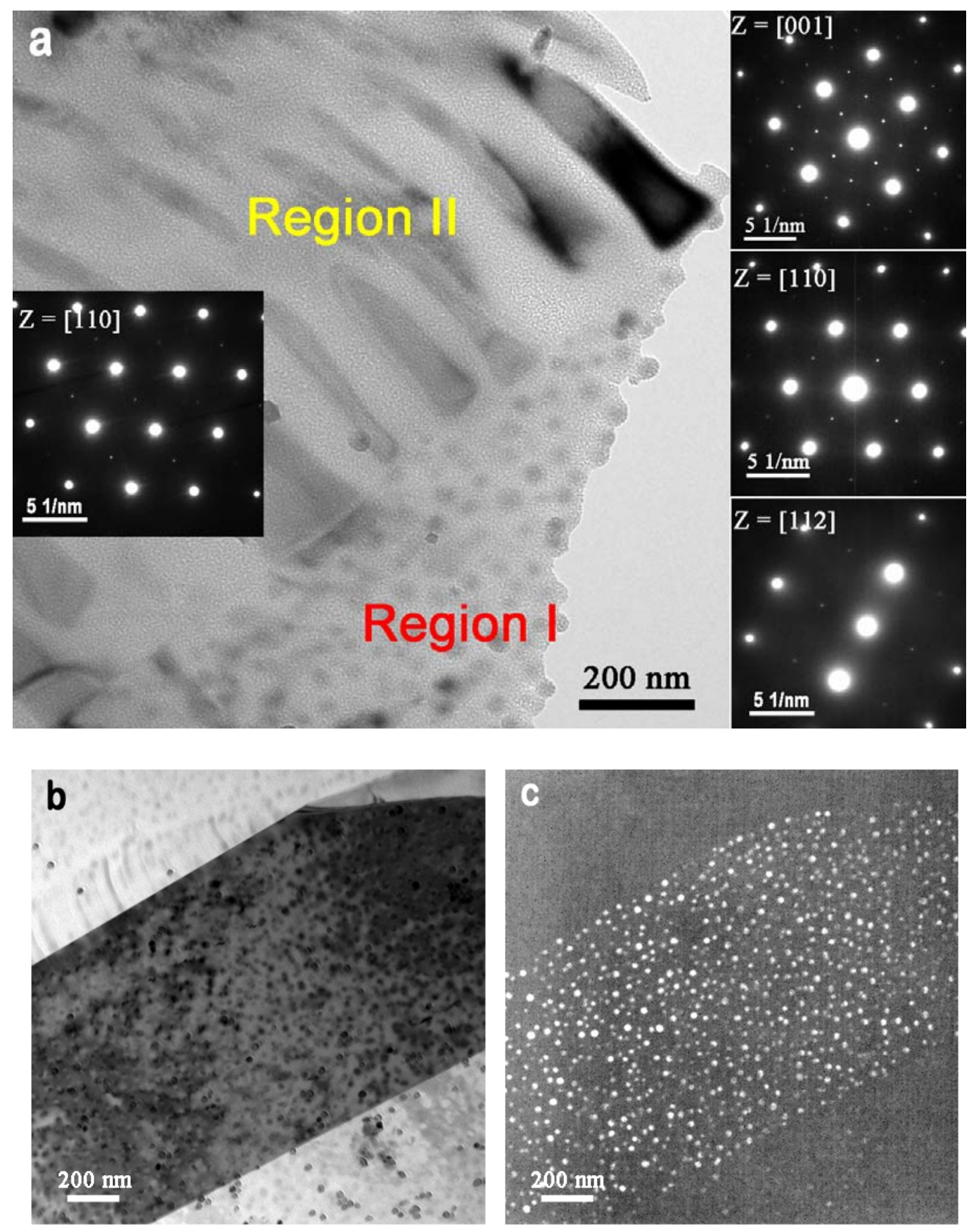


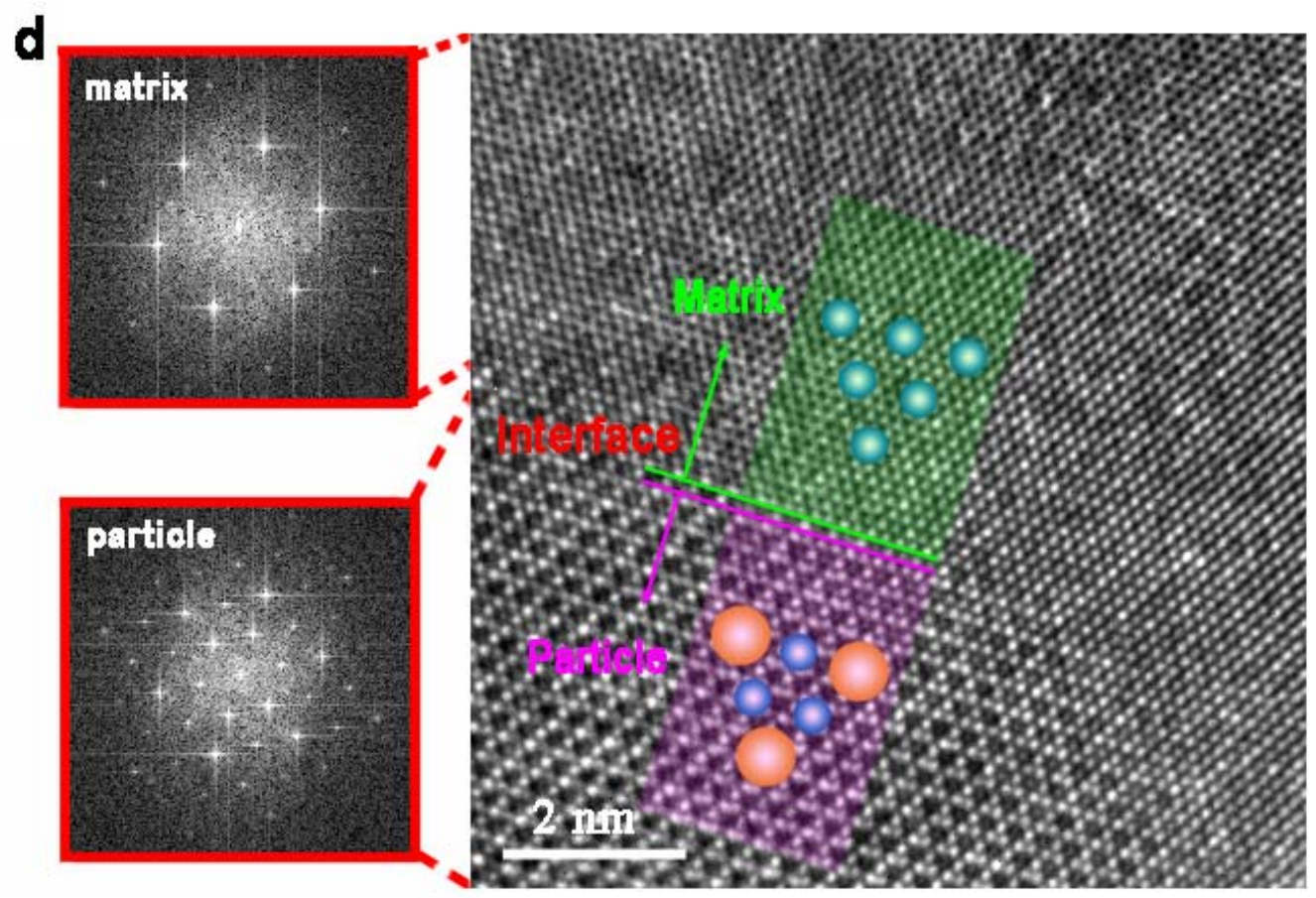


Figure 4

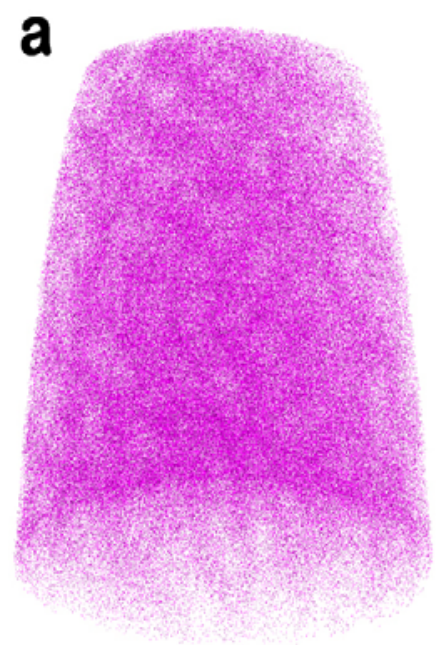

CrFeCo
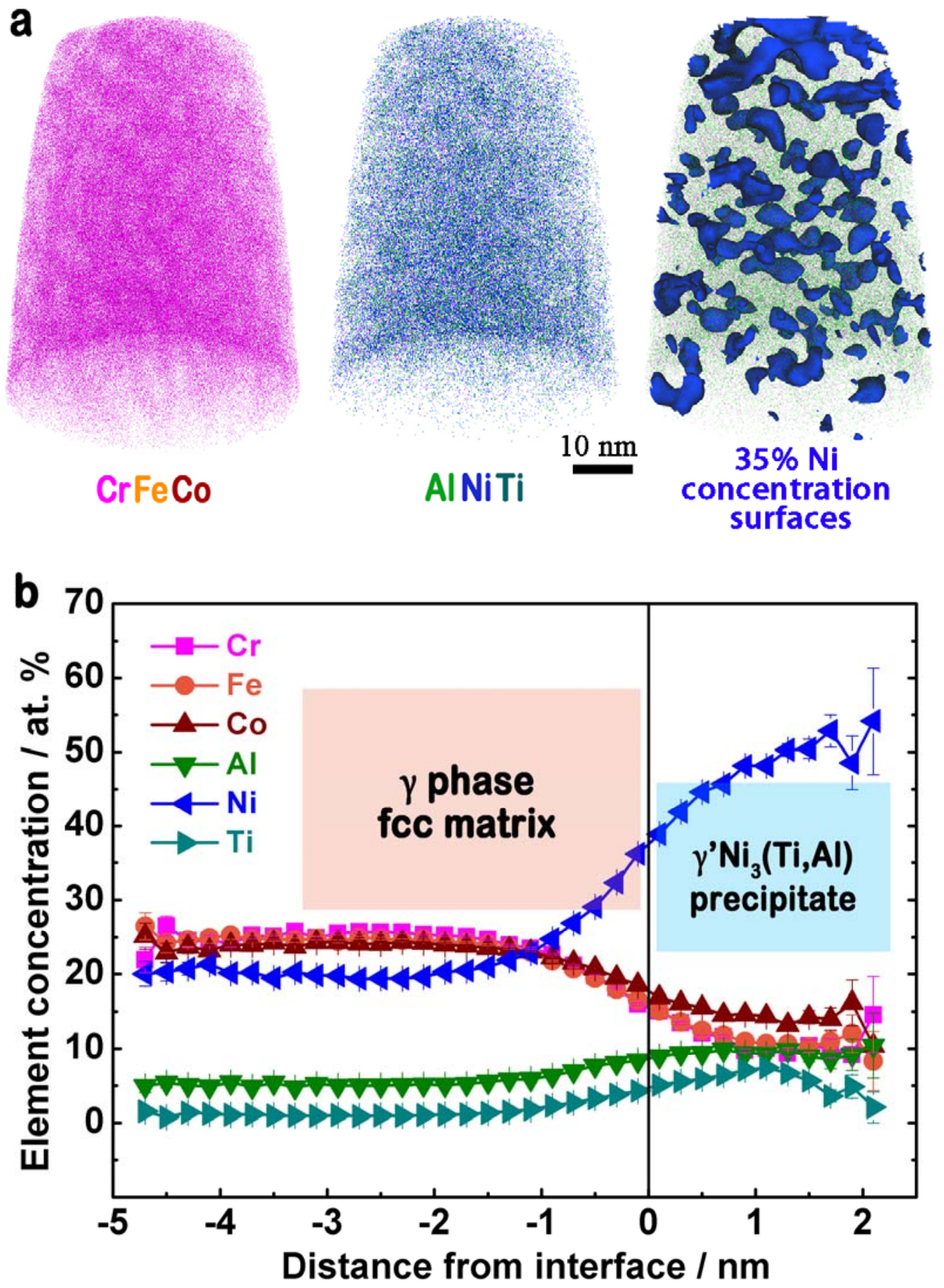
C
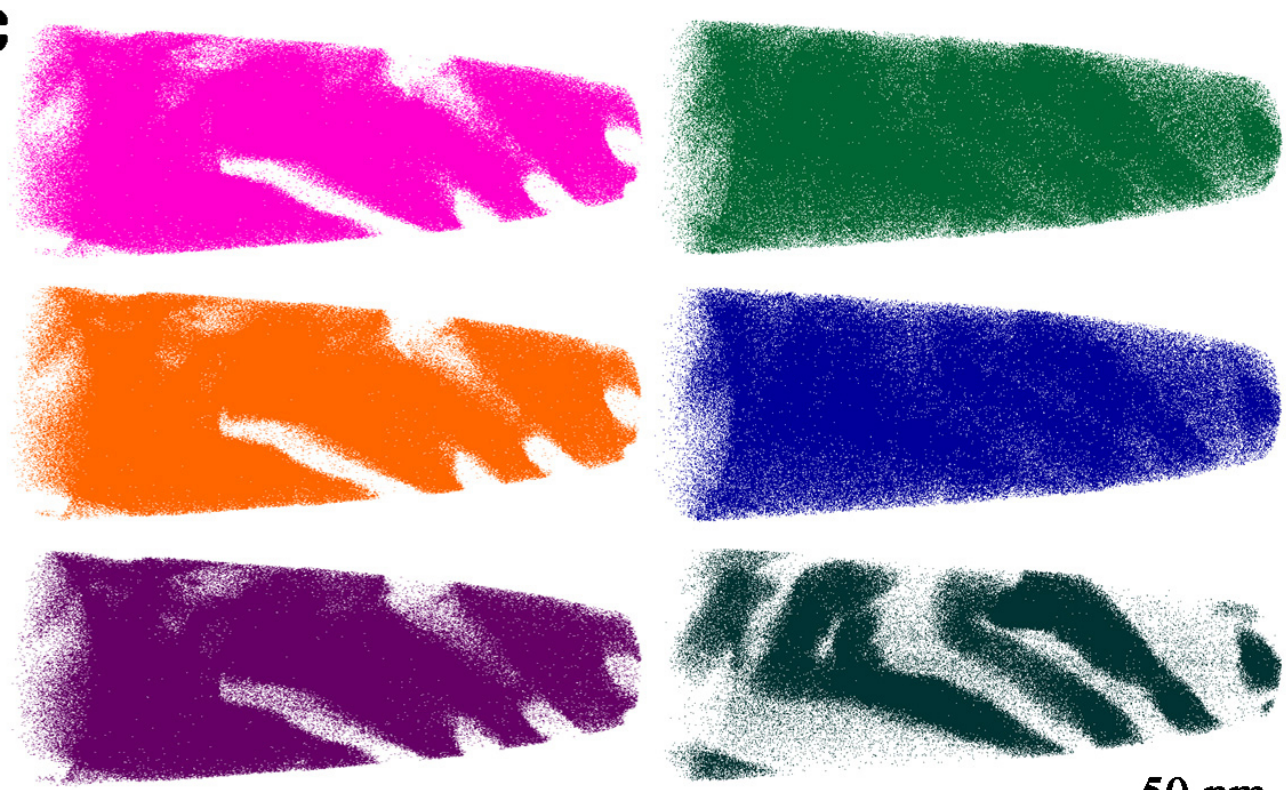

CrFeCo

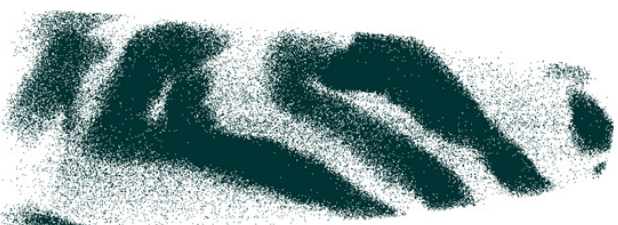

AINiTi

$50 \mathrm{~nm}$

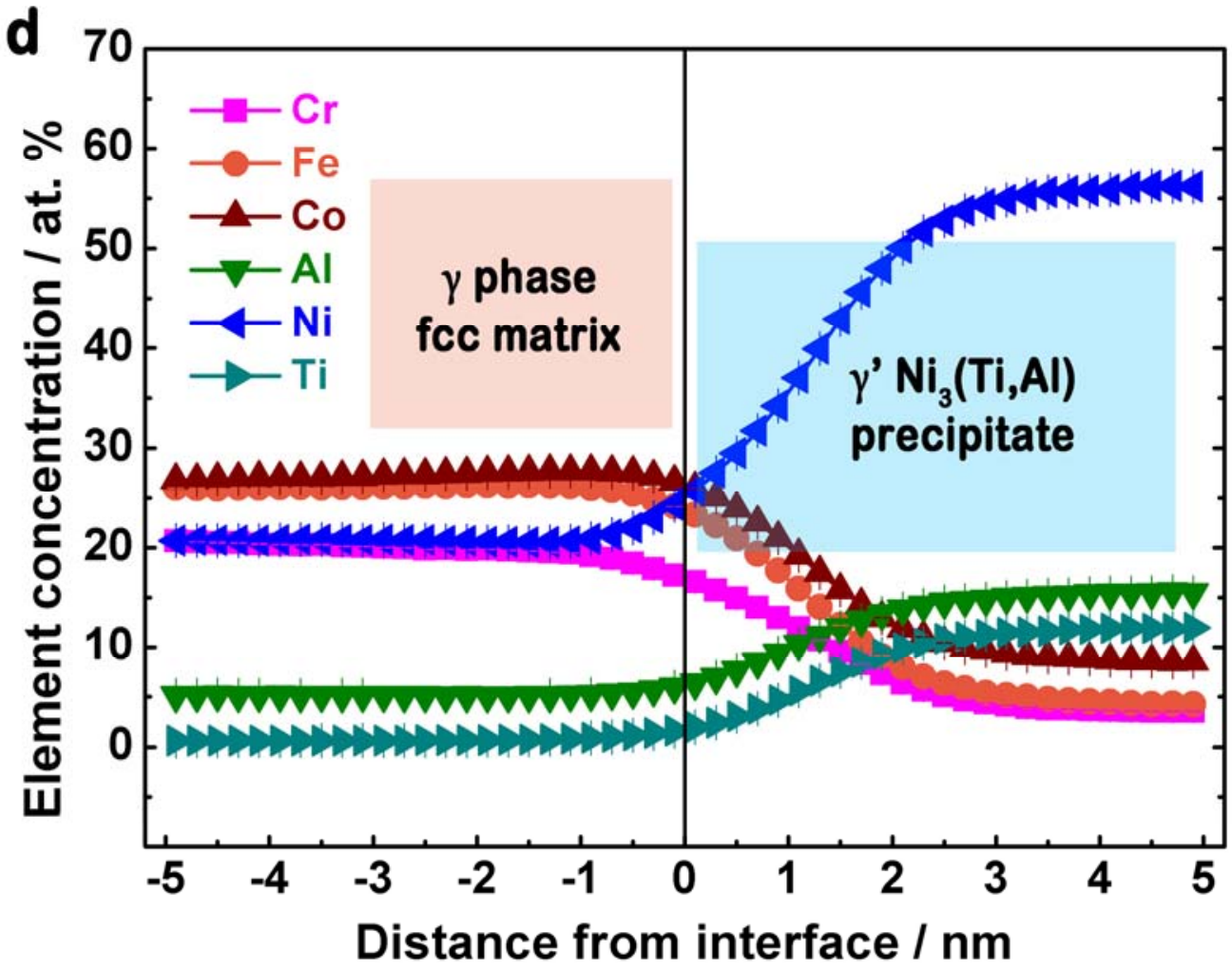


Figure 5
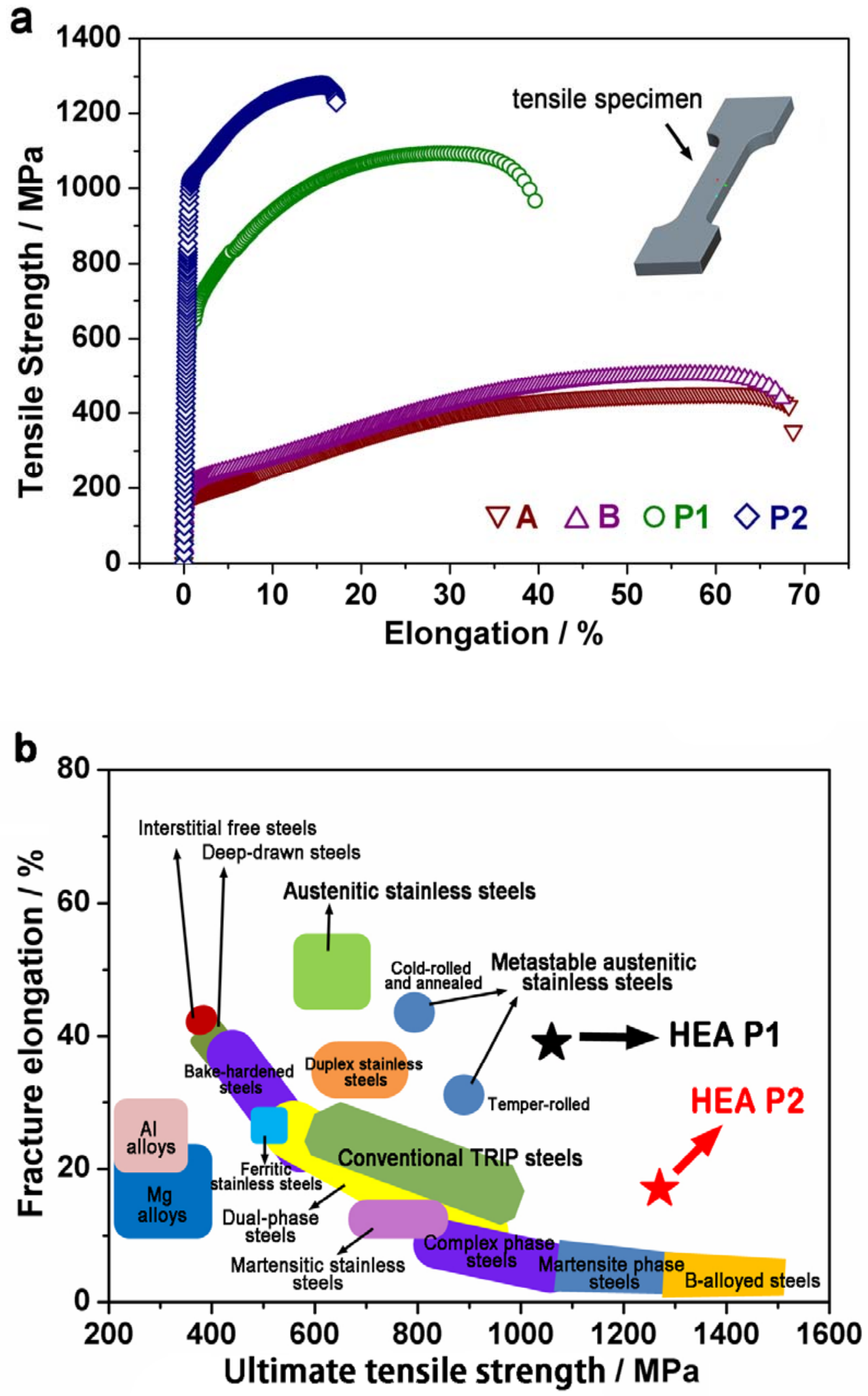
Figure 6

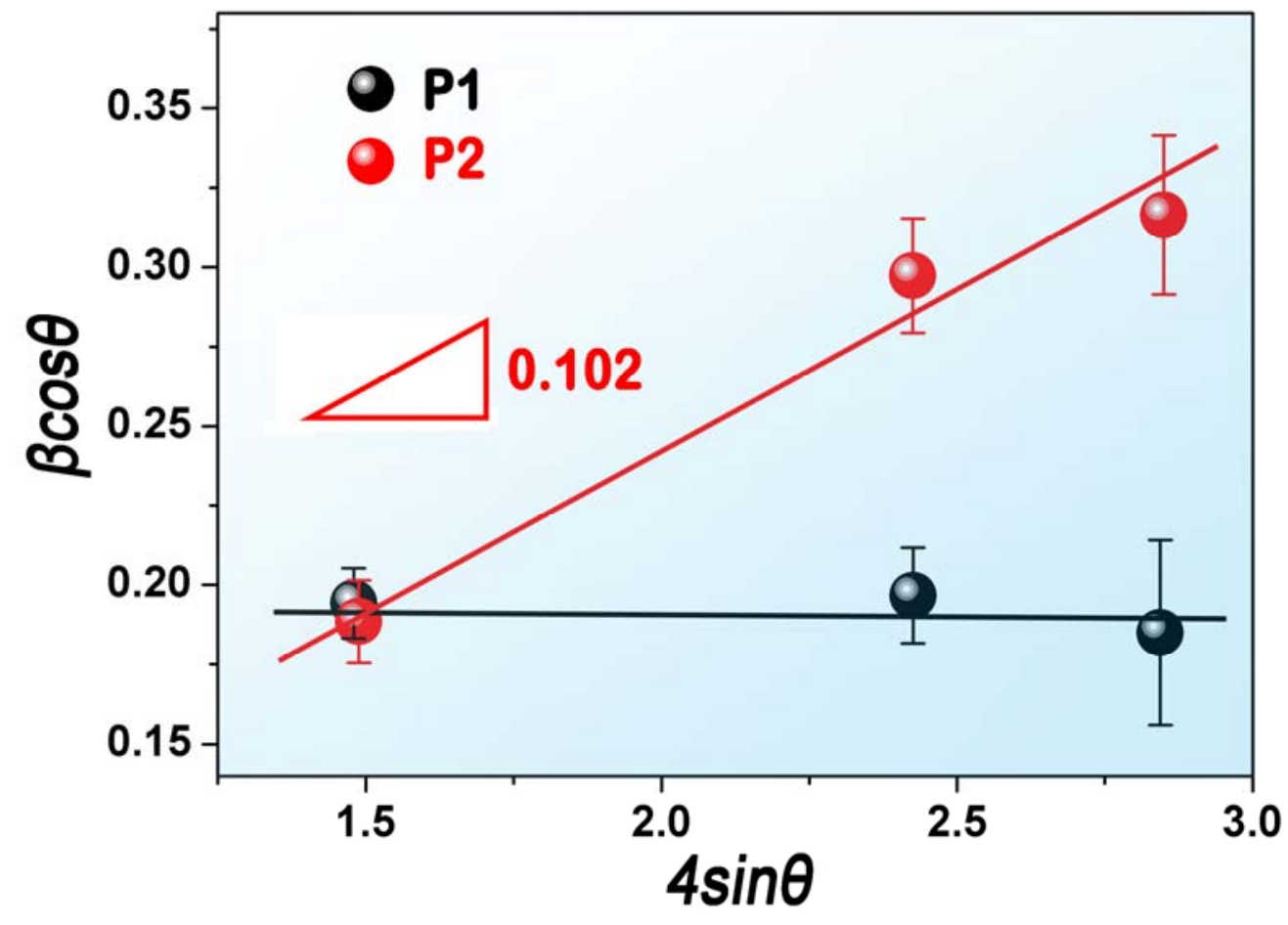

Figure 7

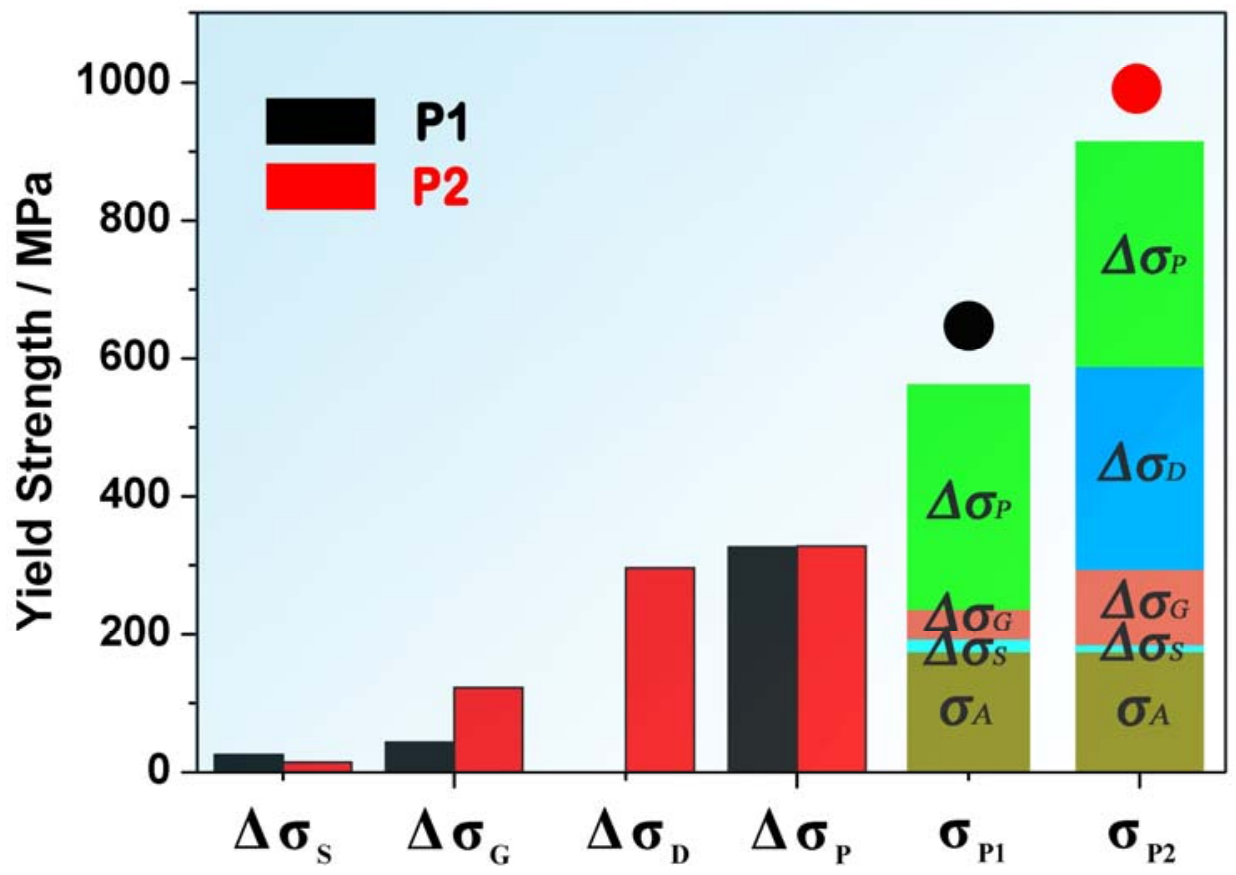

